\title{
Review of current therapy in human immunodeficiency viral infections
}

\author{
PETER G. GULICK, DO
}

\section{The incidence of infection} with human immunodeficiency virus (HIV) continues to increase worldwide. Within the last two years, great strides have been made in understanding the basic pathogenesis of HIV infections, and, based on this knowledge, several drugs that may provide therapy have been developed.

These new agents, especially

azidothymidine (AZT), are being assessed in clinical trials at present. Unfortunately, none is a cure; they simply inhibit the virus from growing. The fact that the virus integrates its genetic material into the genes of normal cells restricts therapeutic options and overall curability. The severe toxicity of these agents also limits their use for many patients. Development of a vaccine seems very unlikely in the next several years. Prevention remains the main mechanism for control of HIV.

Since acquired immunodeficiency syndrome (AIDS) was first recognized as a new disease in 1981 , more than 25,000 cases have been diagnosed in the United States, and 200,000 to 300,000 new cases are estimated over the next five years. ${ }^{1}$ The etiologic agent has been designated as human $\mathrm{T}$ lymphotropic virus type III (HTLV-III), or human immunodeficiency virus (HIV). Since identification of this retrovirus, research has been actively undertaken to discover its basic pathogenic mechanisms, with the ultimate goals of a vaccine (to protect uninfected, but at-risk individuals) as well as antiviral agents (to control replication of HIV in persons already infected).
The purpose of this article is threefold: (1) to define the basic immunopathogenesis of the virus and, therefore, to outline the theoretic basis for using antiviral agents in this disorder; (2) to report on several drugs that are presently under active investigation; and (3) to comment on several new agents that are used to treat some of the opportunistic infections that are caused by HIV-induced immunosuppression.

\section{Immunopathogenesis of HIV}

HIV belongs to a family of viruses that replicate in a retrograde, or reverse, direction (from RNA to DNA). The major structural components of this retrovirus include the core of RNA, group specific antigen (gAg), lipid bilayer, and an outer envelope (env) glycoprotein. Fig 1 summarizes basic stages of viral replication and potential intervention of antiviral medication at the various stages. ${ }^{2}$

The first step in HIV infection is attachment to the target cell. The env glycoprotein mediates binding to the $\mathrm{CD}_{4}$ receptor structure of the target cell. ${ }^{3}$ Theoretically, one may be able to inhibit this initial binding step by monoclonal binding antibodies. Another possibility would be a vaccine that would induce the production of neutralizing antibodies to the $\mathrm{CD}_{4}$ receptor.

After binding, the HIV enters the target cell by a poorly defined mechanism. Once in the cell, the viral reverse transcriptase (RT) makes a DNA copy of the viral RNA. ${ }^{4} \mathrm{RT}$ is a unique viral enzyme. Most of the drugs currently being investigated for use against AIDS are inhibitors of RT. After the viral DNA is formed, it is integrated into the host cell genome by an integrase type of enzyme.

At this point, the virus may exist in two forms: The infected cell may become activated at some point, thus resulting in the DNA being transcribed 
into RNA, which then could be translated into making new viral products. The final results of this form are destruction of the existing cell and infection of new cells. Or, in the other form, resting Tcells remain infected with HIV latently without being killed. This clinically results in an asymptomatic state, but the potential for activation of the genome could occur at any time. ${ }^{5}$ This stage is also the most difficult to treat, and therapy may have to be administered for the patient's lifetime.

The final stage in HIV replication is the assembly of the virus and budding from the cell surface to infect other cells. Interferons potentially could be used at this stage, because it has been shown that they may interfere with the budding of retroviruses. $^{2}$

Another point to be remembered about HIV therapy is that other factors may be contributing to T-cell destruction besides direct cytotoxicity from the virus. There is evidence that autoimmune reactions or toxic immunosuppressive lymphokines also may contribute to the destruction of the immune system. ${ }^{6}$ In that case, one would have to restore the immune system with healthy cells for improvement to occur. These possibilities provide a rationale for exploring bone marrow transplantation and other types of cellular replacement or immunostimulatory therapy in combination with antiviral chemotherapy.

A third consideration in the treatment of HIV is that these patients experience other disease mainfestations that are not directly related to immunosuppression. In particular, it has been found that the virus can infect the CNS and cause a rapidly progressive dementia or other CNS symptoms. ${ }^{7}$ It also has been proven that there is more viral DNA in the brain than any other tissue. Therefore, an anti-HIV agent should have good penetrability into the CNS.

\section{Specific evaluation of antiviral therapy}

\section{Suramin}

This drug was developed in 1916 and is currently being used in Africa as a treatment for trypanosomiasis. In 1984 , in vitro trials ${ }^{8}$ showed suramin to be an RT inhibitor and, therefore, it blocked the cytopathic effect of HIV on helper T-lymphocytes. Recent clinical studies ${ }^{9,10}$ of patients with AIDS indicated that suramin suppresses the viremia; however, there was no evidence of immunologic reconstitution or clinical improvement. Toxicity, which included elevation of hepatic transaminase levels, fever, malaise, rash, proteinuria, paresthesias, reversible neutropenias, and adrenal insufficiency, was significant. At the present time, therefore, suramin is not recommended as effective therapy for AIDS.

\section{$3^{\prime}$-Azido-3'-deoxythymidine (AZT)}

AZT is a thymidine analogue that inhibits replication of the HIV virus in vitro. According to a 1985 report, ${ }^{11}$ it appears to inhibit RT and, thus, terminates viral DNA-chain elongation. It was found in the same study that the drug could be given orally and yet maintain virucidal levels in the serum as well as in the CNS.

Phase 1 studies $^{12}$ then were initiated; they revealed that AZT was well tolerated over a sixweek period. In addition, some subjects had clinical and immunologic improvement, which was characterized by an increase in the number of T-helper cells, development of delayed hypersensitivity reactions, and weight gain.

Based on these results, a multicenter, doubleblind, placebo-controlled trial ${ }^{13}$ was begun to evaluate AZT's effectiveness and safety in AIDS or AIDSrelated (ARC) therapy. There was a statistically reduced incidence of mortality and frequency of opportunistic infections in the treated group $v$ the placebo group during a period of up to 6 months. In evaluating the immune system in subjects receiving AZT, a statistically significant increase was apparent in both skin test reactivity and in the number of T-helper cells as early as four weeks postAZT initiation; the improvement persisted through 20 weeks of therapy. However, the ability to culture virus from patients receiving AZT continued, so such patients must still be considered infectious. It also appeared that AZT may be more beneficial and less toxic to persons with less severe HIV infection than those with full-blown AIDS.

The toxicity of AZT was evaluated in the same group of patients. ${ }^{14}$ Bone marrow suppression was the major complication (45\%). About $24 \%$ of patients receiving AZT developed severe anemia, which required multiple blood transfusions, while $16 \%$ developed severe neutropenia (neutrophil count, $<500 / \mathrm{cu} \mathrm{mm}$ ), which required dose reduction or discontinuation of the drug.

Gill and associates ${ }^{15}$ described four patients who developed severe bone marrow failure after being treated with AZT. Three had marrow recovery within five weeks, but one remained completely aplastic. Concurrent use of acetaminophen also was associated with a higher frequency of hematologic toxicity. AZT in combination with other retroviral agents is being examined ${ }^{16}$ to see whether any synergism resulting in antireplication of $\mathrm{HIV}$ with re- 
duced toxicity to the patient can be demonstrated.

Other chain-terminating nucleoside analogues $2^{\prime}, 3^{\prime}$ Dideoxycytidine. AZT is but one member of the family of nucleoside analogues that can act as chain terminators in HIV infection. Several new analogues, especially $2^{\prime}, 3^{\prime}$-dideoxycytidine, look promising in that they appear to be inhibitory to the HIV at much lower concentrations, which results in less toxic effects to the patient. ${ }^{17}$ Clinical trials using these agents currently are being performed at the National Cancer Institute.

Ribavirin. An analogue of the nucleoside guanosine, ribavirin has been found to have a broad spectrum of activity against DNA and RNA viruses in vitro. The drug has been used in trials against viral agents such as influenza $A$ and $B$, hepatitis $A$ and $\mathrm{B}$, and herpes simplex and herpes zoster, all with mixed results.

Ribavirin also has been used in phase 1 studies of patients with AIDS or ARC. ${ }^{18}$ This study revealed that clinically, ribavirin treatment was associated with either an increase or maintenance of body weight, which resulted in an enhanced feeling of well being, increased energy, and absence of fever while the therapy continued. Nothing definite could be said regarding the drug's effect on survival. As for the immune system, ribavirin was found to increase the absolute levels of T-helper cells, especially in ARC patients. The lymphoproliferative response to various antigens also improved. Once the drug was stopped, however, the $\mathrm{T}$-helper cells returned to pretreatment levels. $\mathrm{Pa}$ tients with AIDS also showed viral suppression in their blood while receiving ribavirin. The side effects to the drug were minimal, and no patients developed lower blood counts, as was observed with AZT. Therefore, ribavirin, possibly in combination with other antiviral agents, merits evaluation in other controlled trials.

\section{Antimoniotungstate (HPA-23)}

Much of the publicity about this drug occurred when Rock Hudson went to France to participate in HPA-23 trials. It appears to inhibit the virus by binding to RT. Most of the clinical studies have been performed in France; so far, no significant clinical benefits have been seen. ${ }^{19}$

\section{Phosphonoformate (PFA)}

The drug was developed initially for use as a topical ointment in herpes infections. It was found to be a potent inhibitor of RT, and a pilot clinical

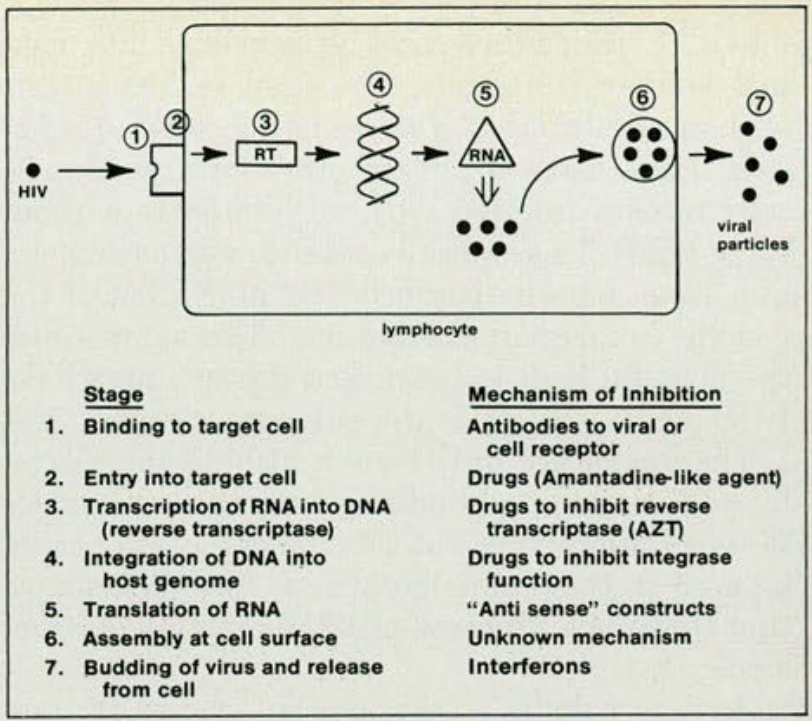

Fig. 1. Basic stages of HIV replication and potential inhibitory mechanisms of antiviral agents at the various stages.

study ${ }^{20}$ was begun in Europe. The results reveal that PFA crosses the blood brain barrier and may have some virostatic effects in vivo. Several trials have just been undertaken in the United States.

\section{Interferons}

First identified in 1957, these proteins are produced by cells when challenged with stimuli such as viral or bacterial infections. Interferons act by binding to specific cell-surface receptors and inducing the production of other proteins with antiviral properties. The mechanisms of interferon-mediated antiviral activities include inhibition of translation, transcription, assembly, and release of viral particles. $^{21}$

Various clinical studies have shown interferons to be active against many different viruses, including rhinoviruses, cytomegaloviruses, herpes simplex and herpes zoster, and hepatitis B. Ho and coworkers $^{22}$ evaluated interferon against $\mathrm{HIV}$ and found it to be active in vitro. Pharmakokinetic analysis, however, revealed that CSF penetration was poor after parenteral infusion. Controlled trials of interferon as a single agent and also in combination with other antiretroviral agents currently are under way.

It should be noted that interferon appears to be active against Kaposi's sarcoma and is being used to treat AIDS patients with this manifestation. ${ }^{23}$

A recent study ${ }^{24}$ compared interleukin 2 with interferon in treatment of infections in AIDS patients. No difference was found between the two groups regarding incidence and severity of oppor- 
tunistic infections. There was, however, a marked disparity in infections by nonopportunistic organisms between the two groups. A higher incidence of bacteremia and localized bacterial infection was seen in patients with AIDS who received interleukin $2 v$ those who received interferon. It is thought that interferon may stimulate depressed neutrophils and myeloid precursors to become activated against bacterial organisms.

\section{HIV vaccine}

Although the antiretroviral drugs may be useful for the control of infection in patients carrying HIV, a vaccine will be needed to prevent HIV in uninfected persons. However, there are several potential problems in developing an effective vaccine. A whole, live, attenuated, or killed virus vaccine could not be used because of the possibility of the viral genetic material incorporating into the host cell and producing live viral particles. Therefore, the development of subunit antigen vaccines would have to be considered. ${ }^{25}$ The difficulty would be identifying that segment of the virus that is stable without heterogeneity and that would be immunogenic but not infectious. Several potential sites of the virus could be used.

Research involving the use of recombinant technology to duplicate the natural surface antigen of the HIV is being carried out. ${ }^{26}$ If it is found that this is immunogenic but not infectious, trials will be made first in the chimpanzee model. Finally, if the vaccine is demonstrated to be safe and effective in humans, it will be given to high-risk, uninfected persons on a wide-scale basis. It is likely, however, that a vaccine will not be available for use until well into the 1990 s.

\section{New agents for treatment of opportunistic infections}

A few drugs that are presently being used to treat some of the opportunistic infections that occur in AIDS patients are discussed briefly in this section:

\section{A-difluoromethylornithine (DFMO)}

This agent has been used experimentally to treat Pneumocystis carinii pneumonia when TMP-SMX and pentamidine have failed. ${ }^{27}$ Some, although not great, success has been seen. Side effects noted on DFMO are thrombocytopenia in $48 \%$ of patients and leukopenia in $16 \% .^{27}$

\section{Aerosolized pentamidine}

This therapy may hold promise in treatment of active Pneumocystis carinii pneumonia as well as pro- phylaxis against it. ${ }^{28}$ Side effects are very few when compared with parenteral administration of pentamidine.

\section{Ganciclovir (DHPG)}

This drug is an analogue of acyclovir. It appears to have activity against cytomegalovirus infections, producing retinal infections, and life-threatening gastrointestinal infections. ${ }^{29}$ It has a narrow margin of safety and produces severe, irreversible testicular damage and neutropenia. ${ }^{27}$

\section{Ansamycin}

This rifamycin- 5 derivative has activity against $M y$ cobacterium avium intracellulare. ${ }^{30}$ This organism, which is resistant to many antituberculous medications, is the most frequent mycobacterial pathogen to infect AIDS patients. Ansamycin had good activity against Mycobacterium avium intracellulare in vitro. However, the clinical experience was disappointing possibly because of low blood levels achieved. The side effects are mainly gastrointestinal irritation and transient liver enzyme elevation. Unfortunately, the disease is still very difficult to control and eradicate.

\section{Spiramycin}

The parasite Cryptosporidium usually causes an acute, self-limiting episode of diarrhea. In AIDS patients, however, it can cause life-threatening illness. There is currently no approved therapy for this organism. Spiramycin has been used in experimental trials and may be therapeutically effective ${ }^{31}$ Still, the overall outlook is grim.

\section{Human granulocyte-macrophage colony stimulating factor (GM-CSF)}

Neutropenia is a major problem in patients with AIDS. It usually occurs during the course of HIV infection and may be a result of the virus or of other viral agents, such as cytomegalvirus or EpsteinBarr virus. Several agents used to treat AIDS patients also can cause neutropenia, which seriously limits their use.

GM-CSF appears to stimulate granulocyte-macrophage precursors to grow. In a study by Groopman and associates, ${ }^{32}$ it was shown that human GM-CSF is well tolerated and biologically active in leukopenic patients with AIDS. This type of strategy, which may increase the number and function of circulating leukocytes, may reduce the morbidity and mortality of infections in patients with leukopenia and may allow us to use agents that have leukopenia as a side effect. 


\section{Summary}

AIDS was first recognized as a clinical entity in 1981. In 1984, three years later, the etiologic agent was identified. Since then, much research has been done in the development of antiviral drugs against the HIV as well as work toward a possible vaccine. Unfortunately, the HIV has several characteristics that make it difficult to control including its ability to integrate into the host genome and lie dormant, its tendency to mutate, and its ability to infect the brain which has limited regenerative potential. Hopefully, in the next few years we will be able to find therapeutic answers to the above problems.

\section{Barnes DM: Grim projections for AIDS epidemic. Science 1986;232:1589-} 1590

2. Yarchoan R: Progress in the development of antiviral therapy for HTLV-III associated diseases. DeVita VT (ed): Important Advances in Oncology, ed 3. Philadelphia, JB Lippincott Co, 1987, p 293.

3. Dalgleish AG, Beverly PC, Clapham PR, et al: The $\mathrm{CD}_{4}$ (T4) antigen is an essential component of the receptor for the AIDS retrovirus. $\mathrm{Na}$ ture 1984;312:763-767.

4. Broder S, Gallo RC: A pathogenic retrovirus (HTLV-III) linked to AIDS. N Engl J Med 1984;311:1292-1297.

5. Hoxie JA, Haggarty BS, Rackowski JL, et al: Persistent noncytopathic infection of normal human T lymphocytes with AIDS-associated retrovirus. Science 1985;229:1400-1402.

6. Lane HC, Masur H, Longo DL, et al: Partial immune reconstitution in a patient with the acquired immunodeficiency syndrome. $N$ Engl $J$ Med 1984;311:1099-1103.

7. Shaw GM, Harper ME, Hahn BH, et al: HTLV-III infection in brains of children and adults with AIDS encephalopathy. Science 1985;227:177182.

8. Mitsuya H, Popovic M, Yarchoan R, et al: Suramin protection of T cells in vitro against infectivity and cytopathic effect of HTLV-III. Science 1984;226:172-174.

9. Cheson BD, Levine AM, Mildvan D, et al: Suramin therapy in AIDS and related disorders: Report of the Suramin Working Group. JAMA $1987 ; 258: 1347-1351$

10. Levine AM, Gill PS, Gohen J: Suramin antiviral therapy in acquired immodeficiency syndrome: Clinical immunologic and virologic results. Ann Intern Med 1986;105:32-37.

11. Mitsuya H, Weinhold KJ, Furman PA, et al: 3'-Azido-3'-deoxythymidine (BW A 50gU): An antiviral agent that inhibits the infectivity and cytopathic effect of human T-lymphotropic virus type III/lymphadenopathy-associated virus in vitro. ProcNatl Acad Sci USA;1985;82:70967100 .

12. Yachoan R, Klecker RW, Weinhold KJ, et al: Administration of 3'azido-3'-deoxythymidine, an inhibitor of HTLV-III/LAV replication, to patients with AIDS or AIDS-related complex. Lancet 1986;1:570-580.

13. Fischl MA, Richman DD, Grieco MH, et al: The efficacy of azidothymidine (AZT) in the treatment of patients with AIDS and AIDS-related complex: A double-blind, placebo-controlled study. $N$ Eng $J$ Med 1987;317:185-191.

14. Richman DD, Fischl MA, Grieco MH, et al: The toxicity of azidothymide (AZT) in the treatment of patients with AIDS and AIDS-related complex: A double-blind, placebo-controlled trial. $N$ Engl $J$ Med 1987;317:192-197

15. Gill PS, Rarick M, Brynes RK, et al: Azidothymidine associated with bone marrow failure in the acquired immunodeficiency syndrome (AIDS). Ann Intern Med 1987;107:502-505.

16. Hartshorn KL, Vogt MW, Chou G-C, et al: Synergistic inhibition of human immunodeficiency virus in vitro by azidothymidine and recombinant alpha A interferon. Antimicrob Agents Chemother 1987;31:168. 172 .

17. Mitsuya $\mathrm{H}$, Broder $\mathrm{S}$ : Inhibition of the in vitro infectivity and cytopathic effect of human T-lymphotropic virus type III/lymphadenopathyassociated virus (HTLV-III/LAV) by $2^{\prime}, 3^{\prime}$-dideoxynucleosides. Proc Natl Acad Sci USA 1986;83:1911-1915.

18. Crumpacker C, Heagy W, Bubley G, et al: Ribavirin treatment of the acquired immunodeficiency syndrome (AIDS) and the acquired immunodeficiency syndrome complex (ARC). Ann Intern Med 1987;107:664674.

19. Rozenbaum W, Dormont D, Spire B, et al: Antimoniotungstate (HPA23) treatment of three patients with AIDS and one with prodrome, letter. Lancet 1985;1:450-451.

20. Farthing CF: Pilot study on treatment of AIDS and ARC patients with intravenous phosphonoformate, abstract. Proceedings of International Conference on AIDS, Paris, June 23-25, 1986, p 35.

21. Sen GC: Mechanism of interferon action: Progress toward its understanding. Prog Nucleic Acid Res Mol Biol 1982;27:105-156.

22. Ho DD, Rota TR, Kaplan JC, et al: Recombinant human interferon alfa-A suppresses HTLV-III replication in vitro. Lancet 1985;1:602-604. 23. Krown SE: The role of interferon in the therapy of epidemic Kaposi's sarcoma. Sem Oncol 1987;14(suppl 3):27-34.

24. Murphy PM, Lane HC, Gallin JI, et al: Marked disparity in incidence of bacterial infections in patients with acquired immunodeficiency syndrome receiving interleukin-2 or interferon. Ann Intern Med $1988 ; 108 ; 36-41$

25. Vogt MW, Martin HS: Prospects for the prevention and therapy of infections with the human immunodeficiency virus. Rev Infect Dis 1986;8:991-1000.

26. Francis DP, Petricciani JC: The prospects for and pathways toward a vaccine for AIDS. $N$ Engl $J$ Med 1985;313:1586-1590.

27. Golden JA, Sjoerdsma A, Santi DV: Pneumocystis carinii pneumonia, treated with A-difluoromethylornithine: A prospective study among patients with the acquired immunodeficiency syndrome. West $J$ Med 1984;141:613-623.

28. Montgomery AB, Luce JM, Turner J, et al: Aerosolized pentamidine as sole therapy for Pneumocystis carinii in patients with acquired immunodeficiency syndrome. Lancet 1987;2:480-483.

29. Wood MJ, Geddes AM: Antiviral therapy. Lancet 1987;2:1189-1192. 30. Woodley CL, Kilburn JO: In vitro susceptibility of Mycobacterium avium complex and Mycobacterium tuberculosis strains to a spiropiperidyl rifamycin. Am Rev Respir Dis 1982;126:586-587.

31. Portnoy D, Whiteside ME, Buckley E III, et al: Treatment of intestinal cryptosporidiosis with spiramycin. Ann Int Med 1984;101:202-204. 32. Groopman JE, Mitsuyasu RT, DeLeo MJ, et al: Effect of recombinant granulocyte-macrophage colony-stimulating factor on myelopoiesis in acquired immunodeficiency syndrome. $N$ Engl $J$ Med 1987;317:593598.

From the Department of Internal Medicine (Oncology and Infectious Diseases), Michigan State University-College of Osteopathic Medicine, East Lansing, Mich.

Reprint requests to Dr Gulick, MSU/COM, B-318 W Fee Hall, East Lansing, MI 48824. 